\title{
Satzung und Geschäftsordnung
}

\section{der \\ pädiatrischen Section \\ der \\ Gesellschaft für Heilkunde \\ zu Berlin.}

§1. Die von der Gesellschaft für Heilkunde in Berlin am 24. April 1879 begründete ,pädiatriselie Section" stellt sich zur Aufgabe, bei der immer wachsenden Bedeutung der Kinderheilkunde ihre Mitglieder dauernd zu gemeinsamen Arbeiten zu vereinigen.

$\S 2$. Die Section, als Glied der Gesellschaft für Heilkunde, erkennt deren Satzungen als für sich bindend an. Die Mitglieder der Section, soweit sie nicht in Berlin wohnen, treten als ausserordentliche Mitglieder in die Gesellschaft ein.

§3. Die Section veranstaltet alljährlich im Laufe des Frühjahres öffentliche Versammlungen in Berlin.

§ 4. In der ersten dieser Versammlungen wăhlt die Section durch einfache Stimmenmehrheit einen Vorsitzenden und zwei Stellvertreter desselben.

Diese bilden in Gemeinschaft mit einem Schriftfïhrer und den Schatzmeister der Gesellschaft für Heilkunde (oder einem Vertreter desselben) den Vorstand der Section und haben während des nächsten Jahres die Geschäfte zu führen.

In den öffentlichen Versammlungen cooptirt der Vorstand nach Bedürfniss einen oder zwei Schriftführer.

$\S 5$. Der Beitrag der Mitglieder der Section ist für das Kalenderjahr auf fünf Mark festgesetzt.

Der Schatzmeister ist befugt, den Jahresbeitrag event. durch Postmandat einzuziehen.

$\S 6$. Die Verhandlungen der Section werden gedruckt. Jedes Mitglied der Section erhält unentgeltlich ein Exemplar derselben. (Auch erhält jedes Mitglied die übrigen Publicationen der Gesellschaft.) 


\section{Geschäfts-Ordnung.}

§ 1. Der Vorsitzende setzt die Tagesordnung fest, bestimmt die Reihenfolge der Vortrāge und etwaiger Demonstrationen und leitet die Verhandlung.

§ 2. In der Regel sind für jeden Vortrag 30 Minuten angesetzt, doch hat der Vorsitzende das Recht, ohne Befrsgung der Versammlung für die Daner desselben 40 Minuten zu gewähren. Nach Ablanf dieser Zeit hat die Versammlnng durch Abstimmung über die weitere Fortdauer zu bestimmen.

§ 3. Die Reden in der Discussion dürfen 5 Minuten dsuern; der Vorsitzende kann jedoch 10 Minuten Dauer gestatten, es sei denn dass die Versammlung durch Abstimmung auf Antrag eine andere Willensmeinung kundgiebt.

§ 4. Anträge, welche der Beschlussfassung der Versammlung unterliegen, sind dem Vorsitzenden schriftlich einzureichen. 